\title{
CHICKEN-BLOOD STONE FROM CHINA
}

\author{
By Wang Fuquan and Guo lingfeng
}

"Chicken-blood" stone is one of the most prized ornamental materials in China, especially for use in elaborate carvings and seals. A fine-grained mixture of dickite/kaolinite and quartz, with varying amounts of red cinnabar, chicken-blood stone is found in only two localities in China: Changhua and Balinyouqi. This article describes this material and its gemological properties as well as the occurrence at the two known localities.

One of the most unusual and sought-after carving materials found in China is the rich red "chickenblood" stone (figure 1). Also called Changhua stone or Balinyouqi stone after the sole Chinese sources in Changhua, Zhejiang Province, and Balinyouqi, Inner Mongolia Autonomous Region, chickenblood stone is actually a fine-grained mixture of dickite/kaolinite and quartz that contains varying quantities of minute crystals of cinnabar, which impart the color. To date, Changhua and Balinyouqi are the only known sources of this ornamental material, although it has been distributed throughout Asia and is especially popular in Southeast Asia.

Ancient writings reveal that chicken-blood stone has been known in China for more than 500 years. Listed among the palace treasures of the Ming Dynasty (1368-1644) is a seal carved from this material. Examples of early carvings are on exhibit today in the Imperial Palace in Beijing. Compared to the cinnabar-stained limestone from China reported by Keller and Wang (1986), chicken-blood stone is considered a superior gem material and one of the noblest of all native ornamental stones (Wang, 1979).

The authors have examined a number of representative samples of chicken-blood stone from the above-mentioned localities in Zhejiang Province and the Inner Mongolia Autonomous Region. This report looks at the composition and gemological properties of this material, as well as its occurrence in these two localities.

\section{DESCRIPTION OF CHICKEN- BLOOD STONE: COMPOSITION AND GEMOLOGICAL PROPERTIES}

Chicken-blood stone is actually a rock composed of dickite, kaolinite, quartz, and cinnabar. It should be noted here that earlier references to chicken-blood stone as pyrophyllite, a variety of agalmatolite (e.g., Minerals in China, 1980), are incorrect. Gem-quality chicken-blood stone is rich in cinnabar and semitranslucent to translucent. The body color may be white, yellow, or gray-various mixtures of microcrystalline dickite and kaolinite-with isolated spots, broad streaks, or clouds of dark to bright red cinnabar. Some specimens contain so much cinnabar that they are completely red. In China, the translucent base rock is referred to as dong, and specimens are categorized as white dong, yellow dong, and gray dong (figure 2). Wet chemical analyses of various dong samples by Mr. Wu Zhimin of the Zhejiang Geological Bureau showed that the light yellow color depends mainly on the presence of iron $\left(0.22\right.$ wt. $\left.\% \mathrm{Fe}_{2} \mathrm{O}_{3}\right)$ and that with increasing amounts of iron the color shifts from gray to green $\left(0.41-1.98\right.$ wt. \% $\left.\mathrm{Fe}_{2} \mathrm{O}_{3}\right)$.

The specimens of chicken-blood stone examined by the author have a subadamantine to pearly luster, a specific gravity of 2.6-3.0, and a Mohs hardness of 3 . Since the material is a rock, the refractive index varies considerably, with an average around 1.55-1.56 for the dong. In thin section, the material is transparent. Compact massive, it appears microgranular when observed with a microscope (figure 3).

\section{ABOUT THE AUTHORS}

Dr. Wang is research professor at the Geological Museum of China, Xisi, Beiling, China. Mr. Guo is currently working in the School of Earth Sciences, Macquarie University, North Ryde, NSW, Australia.

Gems \& Gemology, Vol. 25, No. 3, pp. 168-170

(C) 1989 Gemological Institule of America 


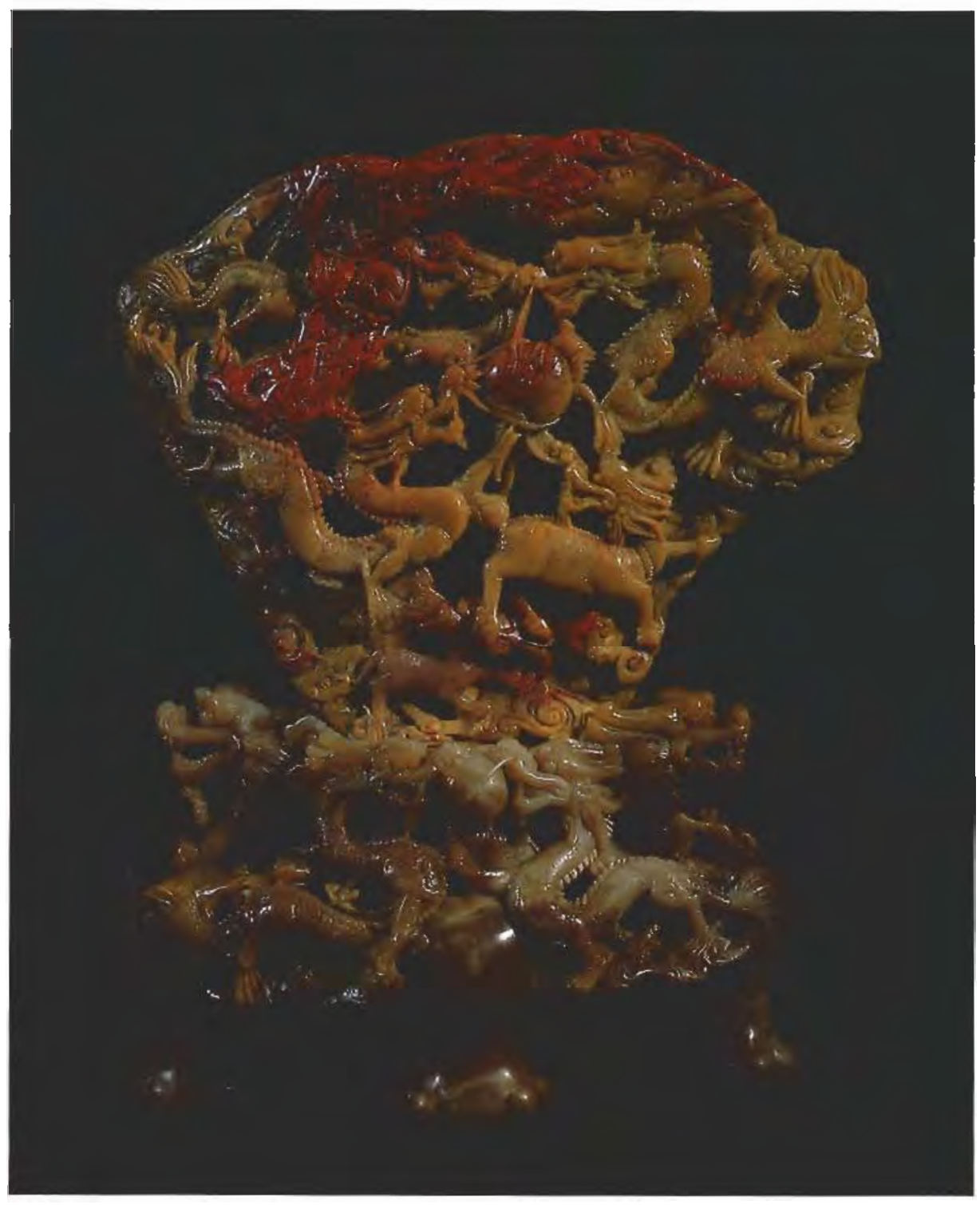

Figure 1. This 16-cm-high fan screen, delicately carved with nine dragons playing with a pearl, is a particularly fine example of chicken-blood stone from China. The material from which this screen was carved is from Changhua, in Zhejiang Province. Courtesy of the Geological Museum of China, Beijing.

Because of the low hardness (especially when compared with jadeite, $61 / 2-7$, for example), this fine-textured material is easily carved with a small knife and lends itself well to intricate details. Its value depends on the amount of bright red coloration, the transparency of the dong, and the overall clarity. The more of the bright red a piece contains and the cleaner it is, the greater its desirability. A fine $10 \times 2.5 \times 2.5 \mathrm{~cm}$ seal made of chicken-blood stone recently sold for more than US $\$ 3,000$ in China. On exhibit at the Geological Museum of China are some exceptional carvings from this material (see, e.g., figure 1).

\section{GEOLOGY AND OCCURRENCE}

In China, carving-quality chicken-blood stone has been found only in Cretaceous and Jurassic altered volcanic rocks-for example, welded tuffs and rhyolite-in which it generally occurs in bedding fracture zones. The larger masses commonly display porphyritic texture, as shown in figure 2 , with substructures that resemble veinlets, disseminations of included material, cloudy areas, and, in places, brecciation. More than one vein may be found in a fracture zone; the veins usually exceed $15 \mathrm{~cm}$ in width and $10 \mathrm{~m}$ in length. Common associates in the veins are dickite, kaolinite, quartz, sericite, and pyrite. The presence of these species suggests that the host rock has been epithermally altered. The occurrence of chickenblood stone at Changhua has been described in Cheng, et al. (1986). 


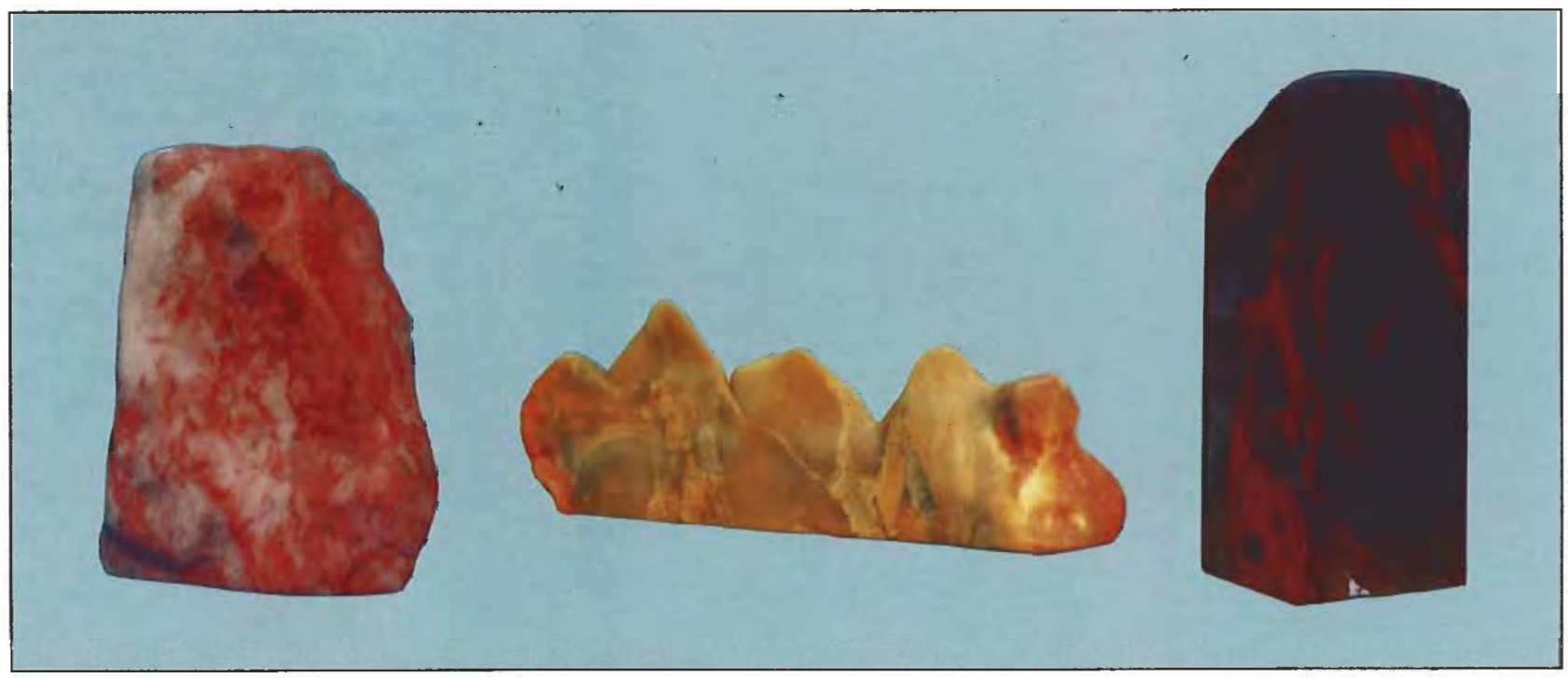

Figure 2. Left: The base rock in this example of chicken-blood stone is referred to as white dong in China. Center: This pen rack is carved from yellow dong chicken-blood stone. Right: This seal has a deep gray dong groundmass. All three specimens are from Changhua.

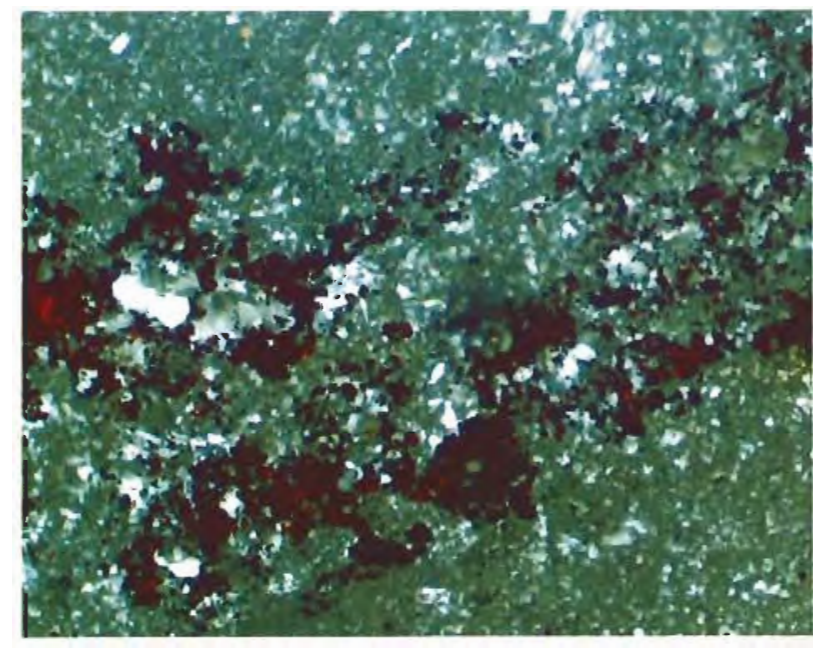

Figure 3. With microscopy, spots of disseminated cinnabar can be seen in a microgranular groundmass of dickite and kaolinite. Crossed nicols; magnified $25 \times$

At the Changhua occurrence, which one of the authors (WF) has visited, all mining for this material is in underground tunnels. Access to the actual mining operation was restricted at the time of the visit, so details are unavailable for this report. Although economic quantities of the material are being produced, precise production figures have not been released.

\section{CONCLUSION}

Significant quantities of chicken-blood stone are now being mined from the localities at Changhua, in Zhejiang Province, and Balinyouqi, in Inner Mongolia Autonomous Region. The presence of cinnabar in this rock provides splashes of a rich red color. Because it is so soft, it is commonly used for carvings, for large pieces as well as for seals and beads.

\section{REFERENCES}

Cheng D., Zhau D., Tang Z., Zheng Z. (1986) Research on mineralogy and genesis of bloodstone gem in Changhua, Zhejiang Province. Kexue Tongbau (Science Bulletin), Vol. 31, No. 13, pp. 918-923.

Keller P.C., Wang F. (1986) A survey of the gemstone resources of China. Gems ef) Gemology, Vol. 22, No. 1, pp. 3-13.

Minerals in China (1980). Shanghai Scientific and Technical Publishers, Shanghai, China.

Wang F. (1979) Precious stones found in China. Lapidary Joumal, Vol. 33, No. 3, pp. 694 and 696. 